\title{
Criteria for Long-Range Nuclear Control Policies
}

\author{
Herman Kahn* and Carl Dibble***
}

Problems of Public policy may look very different depending on the P time perspective in which they are viewed. The problem of nuclear proliferation is an example. Between the early nineteen forties and the mid-fifties five nations (not including Nazi Germany) began nuclear weapons programs. All five were successful in acquiring weapons and delivery capabilities. From the mid-fifties to the mid-sixties, however, not a single nation is known to have set out on a deliberate program of nuclear weapons procurement. If an observer's perspective were limited to the earlier period, he would reasonably anticipate fast-paced and widespread proliferation in the future. From the experience of the last decade, on the other hand, one might draw lope that profound obstacles exist to the spread of nuclear weapons, and that the number of nuclear powers in the world may be no larger by the late seventies or even the eighties than it is today. Yet optimisin must be tempered if one calculates how much easier and cheaper it will probably be for nations to deploy nuclear weapons in the coming decade or two. The sixth nuclear power will probably be able to acquire capabilities roughly similar to those of France or China today without duphicating their efforts. If there are any decisive obstacles to nuclear proliferation, they will not be technical or financial.

Looking three or four decades ahead, we cannot foresee with assurance any reliable roadblocks to widespread proliferation. Proliferation is therefore a long-range problem; yet present proposals are all shortrange remedies intended to maintain the status quo. ${ }^{1}$ Admittedly, one could argue that some aspects of the problem can only be understood concretely and dealt with effectively as a series of short-run problems. But in the early 1970's proliferation may appear to be a radically different kind of problem than it does to various observers today. As a result we could not be entirely reassured even if one of the plans that is currently being seriously discussed were adopted. Other feasible solutions are not being discussed because of the neglect of long-range issues. Moreover,

\footnotetext{
* B.S., 1945, University of California; M.S., 1948, California Institute of Technology; Director, Hudson Institute.

A.B., 1956, Harvard University; M.A., 1961, University of Chicago; Staff Member, Hudson Institute.

1 Given the current political situation it is almost inconceivable that any non-nuclear nation, except possibly for India, would be willing to launch a national nuclear program in the next five, or perhaps ten, years. Therefore, for this period of time any plan will work. The major issue is what will happen after 10 or 15 niore years.
} 
there are other nuclear problems besides proliferation; yet much present discussion of nuclear proliferation ignores its relationship to other arms control problems.

A more imaginative approach to the problems of nuclear weapons in the next few decades might result from our making an inventory of criteria by which any proposed nuclear control measures could be evaluated. Such an inventory should do more than assemble the established criteria, since criteria change. Not infrequently a vital public need is successfully fulfilled by adoption of a given policy, but this policy then assumes a ghostly kind of power and authority which endures long after conditions have changed, distracting attention from emerging and continuing problems. Yesterday's great issue is often precisely what slould not be focused on today. The imventory should therefore emphasize medium range (5-15 years) and long range (10-30 years) criteria.

Although we cannot discount criteria of passing or contingent importance when considering new nuclear proliferation policies, we should put a premium on those that look useful in the long run. Such criteria should help in anticipating problems, scanning for solutions and making preliminary evaluations. Moreover a survey of long-run criteria or desiderata need not be cramped by current estimates of feasibility. Though some criteria may seem impractical today, a future nuclear war or crisis, or merely the passage of time may create an unprecedented opportunity or make a seemingly distant problem suddenly vital. Many "impractical" or low-priority measures which meet a variety of criteria can be planned in advance and implemented when the opportunity arises.

The hist below is intended to be suggestive, not definitive. It is designed to stimulate debate and discussion on a broad and objective basis rather than on a narrow or partisan one. Novel suggestions, objectivity and intellectual stimulation may of course rouse sleeping dogs-may bring up matters that many would prefer to ignore. But we feel that the negative effects are likely to be trivial or worth accepting. ${ }^{2}$

\footnotetext{
2 It should be noted that almost any serious consideration of arms control issues has this effect of "rocking the boat." Winston Churchill pointed out during the interwar yenrs that arms control conferences are more effective in this respect than attempts to raise the issues by private individuals. He noted that governments are often willing to allow abstruse and esoteric defense issues to lie dormant-in part because other issues are politically more pressing, in part because consideration and disposal would arouse controversy, and in part because such defense problems are techmical, difficult, and time consuming. None of these reasons applies if the government is being asked to agree publicly to a treaty which permanently forbids actions designed to meet the dormant issue. Arms control conferences raise questions in such a dramatic, immediate, and politically sensitive way that they must be seriously considered rather tban being deferred indefinitely. Furthermore, senior members and bureaucrats of the government become educated in the nuances of the problem and the no longer dormant and neglected issues may, as a result, arouse
} 
The criteria listed include the recognized criteria of military policy and arms control-among them deterrence and damage-limitation in a broad sense of the term. The list also includes less familiar criteria which are nevertheless either unquestionably or possibly important, as well as several items which focus on the issue of medium-to-long-range political feasibility.

In scanning and selecting criteria we have been aware that mediumrange problems and goals are often left quite obscure even when the nearest and most distant points are envisaged clearly. Perhaps our own list is a failure on this score; some time from now it miglit appear to have concentrated on a few immediate problems and one or more far-distant goals. While in selecting criteria we have tried to avoid narrowness in perspective and partisanship, there may be bias in the list and in the discussion, notably because of our interest in the idea of stripping prestige and utility from nuclear weapons.

A desirable long-range arms control pohicy for nuclear weapons should satisfy the following criteria:

1. It should limit proliferation without necessarily freezing the current nuclear status quo. The policy should therefore be based neither on preserving intact the current security arrangements of the leading powers, nor on the imposition of a permanent and total ban on the non-nuclear powers. The most satisfactory solution may be to limit future proliferation to regional or international organizations.

very intense interest. This interest often results in programs which would never have been started if the professionals or special pleaders had not been able to get the ear of their colleagues and seniors. Similarly arms control conferences draw the attention of the opposition to the government's now obvious lack of action in developing nuclear capabilities. Before an arms control conference no one would have suspected invidious reasons for this lack of action; they would attribute it to bureaucratic inertia. But once the issue of a permanent ban has been raised by the arms control conference, those urging inaction and neglect are making a conscious and active political choice rather than following the path of burcaucratic inertia. Indeed, issues which are not only dormant but which did not even exist can now be aroused in the momentous and controversial atmosphere of an arms control debate. The current conferences in Geneva on nonproliferation are apparently producing this effect. Almost every government which has a serious potential for nuclear weapons has been forced to ask itself some searching questions-particularly India, Japan, West Germany and even Italy. As a result semior administrators in all these countries are now focusing inuch inore attention on nuclear technology and what they stand to lose by abstention than they would have if there had been no conference on nonproliferation. Indeed, one can argue rather persuasively that in many countries there has been an acceleration of current programs for the peaceful use of nuclear energy as a result of this aroused attention and concern.

In short, while an arms control conference can give new impetus to various proposals for restricting the possession and use of nuclear weapons, it inay also stimulate certain fence-sitting countries to enter the nuclear race now, for fear of being permanently foreclosed. A similar negative effect could result merely from the publication of this article, but the risk in this case seems insignificant. 
2. It should seek to create international attitudes and concepts which will minimize the temptation to use nuclear weapons. Antinuclear bias should be encouraged, and the use of nuclear weapons should be considered illegitimate except for limited proportionate retaliation. These attitudes would improve current standards of international behavior without requiring complete reform.

3. It should meet both of the traditional criteria of arms controldeterrence and damage-limitation.

4. It should be flexible enough to withstand crises and to be negotiable in the light of relevant national interests. However, in its essential elements it should represent, at least potentially, a permanent policy.

In discussing these groups of criteria, we will concentrate on elaborating and clarifying the issues rather than advocating any particular solution, althougll we have included brief suggestions on the merits of $l e x$ talionis and regional defense organizations. ${ }^{3}$

I

\section{IIMITS ON PROLIFERATION}

While the theoretical arguments supporting the almost unanimous public consensus that nuclear proliferation should be severely limited may not be as solid as commonly thought, almost all the analysts, as well as government officials and the man in the street, seem to feel that the argunents against prohferation are convincing. While we agree with this consensus, we do not believe it is likely that a stable international system of nonproliferation will, in the long run, be identical with the current situation in which four of the permanent member-nations of the Security Council and the Chinese People's Republic are the only nations with nuclear weapons. If a limitation were to be agreed on today, this one seems as reasonable as any. It requires that the losers of World War II -the potentially revisionist powers of Japan, Italy and Germany-remain non-nuclear indefinitely. Conceivably, others besides the victors in that war miglit wisli to perpetuate such a situation. But it may be unproductive to tell the losers of that war in effect that until they win a war, they will remain second-class powers. We believe that the concept of "eternal" limitation on the defeated major powers, though potentially

${ }^{3}$ A companion paper, H. Kahn, Nuclear Proliferation and Rules of Retaliation, 76 YaLE L.J. 79 (1966), discusses in greater detail some general proposals intended to meet the criteria set forth in this paper. While the checklist in this paper is focused on nuclear proliferation, similar checklists can be prepared, often including many of the same points, for other arms control and national security issues. Both papers are taken from a forthcoming Hudson Institute Report by the present authors that contains a much more detailed discussion of the basic issues. 
beneficial, is a long-run weakness in the current system. ${ }^{4}$ For this reason, while limiting proliferation is one of our highest priority objectives, we refuse to concede that this necessarily implies an effort to freeze the current nuclear status quo-for the rest of history or even for more than a decade or so.

\section{A. Avoiding the Perpetuation of the Postwar Two-Power World}

A nuclear control policy should not be aimed mainly at perpetuating current security arrangements and hierarchies. Although the prestige, morale and influence of the leading powers cannot be ignored, no stable policy can be based on an assumption that the two-power world of the postwar era will continue to exist.

For some two decades the obligations and involvements of the United States in world affairs have grown more extensive-from Europe to the Middle East, from the Far East to Southeast Asia, from military and economic aid to extensive foreign deployments and capital investments, from a few specific roles to several complicated ones. This trend has been persistent despite some sincere efforts from time to time to stop it or slow it down. But in the mid-sixties hardly anyone would argue that the trend can continue indefinitely, and not many would say that the current situation can be long maintained. Therefore we might expect wide, nonpartisan agreement on this criterion: A long-range nuclear control pohicy should not aim at perpetuating, nor depend on perpetuating, America's preeminent status and accumulated obligations of the last twenty years. The same applies to the Soviet Union.

Of course in the last few years there has been controversy, perhaps growing in intensity, over the general direction of American foreign and defense policy. Isolationists and interventionists of the 1930's seem to have their connterparts in the "neo-isolationists" and "globahists" of the 1960 's. On the one side it is argued that the United States is overcommitted, overstraining its morale, squandering its resources, and imprudently risking important assets and programs. On the other side, the United States has obligations to its allies and to the world at large to meet commitments and defend world stability, and the costs of reducing our commitments would be enormous even if sometimes not immediately apparent. Moreover, by shirking its obligations, the United States would

4 It is startling to compare how concerned most statesmen were with this problem in the late forties when the defeated powers were weak and friendless and how unconcerned they seem today when West Germany has the third largest gross national product and is the second largest trading nation in the world, and Japan has-by idiosyncratic but reasonable calculations-the third largest gross industrial product and is growing more rapidly than any other state. 
open the path to totalitarian aggression and subversion, and to renewed morale, élan, and dynamism among our enemies.

At the present time, it is probable that most people have not frozen their positions on either side of the argument. Undoubtedly almost everyone would hike to find some way to reduce American commitments safely and honorably. Few would argue for abrupt withdrawal and abandoning commitments. Rather, many people are looking for something like limited and specific disengagement without irresponsibility towards the outside world, or for some sort of decent and prudent limitation and restraint on American involvements abroad.

To say that a long-term nuclear weapons policy should not be aimed at perpetuating United States or Soviet preeminence is not to advocate isolationism or to belittle American obligations. It is not even necessarily a very controversial statement, if taken together with other desiderata. At the same time it is not a trivial statement if, as we believe, there might be unsuspected possibilities of reducing "super-power" burdens without creating dangerous vacuums.

The nonproliferation treaty currently being negotiated at Geneva may have a tendency to go in exactly the wrong direction. It would increase inordinately United States and Soviet obligations by giving sweeping nuclear guarantees to nonnuclear powers without increasing significantly the participation of others in this new form of "collective" security. In effect it assumes a perpetuation of the postwar two-power world and almost ignores its growing multipolarity.

\section{B. Avoiding an Unnecessarily Inferior Status for any Country}

A nuclear control policy should not require France, the United Kingdom, Japan, India, West Germany, or Italy (in roughly this order of priority) to accept an invidiously inferior nuclear status or an unnecessarily precarious or dependent security position. Similar provisions may eventually be necessary for Brazil, Mexico, Argentina, Indonesia, Pakistan, Australia, and perhaps others.

One could of course make a much longer list of countries which should not be asked to accept an invidiously inferior status or an unnecessarily precarious security position. The first six countries cited include most major American allies (plus India) which are likely in the future to pose the greatest difficulties for a long-term policy of limiting the functions of nuclear weapons. In five or ten years, if not now, these countries are likely to seek an even more independent status in the world than they enjoy under current conditions. Any one or many of them might, like France, attempt to exploit the advantages of both independence and interde- 
pendence by acquiring and bargaining with their own nuclear weapons, thus trying to lay a basis for future independence.

This is an important criterion. Indeed, one reason to search for new proposals is that many proposals currently being discussed fail at just this point: A "perpetual" ban on the acquisition of nuclear weapons in any form by rising powers-when such acquisition may, in the absence of regional or other international arrangements, seem necessary for leadership, status or independence, or for protection of some valued security interests-does not seem very durable. One can therefore predict that, if the draft treaty on the proliferation of nuclear weapons is ratified, it will sooner or later fail in its major objective of restricting possession of nuclear weapons to the five victors of World War II.

An even more basic point can be made. It has listorically been true that when one nation is the protector of another, the first nation has a degree of control over the second nation's affairs. While this seems to be much less true today, insofar as there is a relationship of nuclear protector and protectorate, to a certain degree the condition persists and there seem real possibilities that the hierarchic nature of these relationships will increase in the future. In any case, no nation can be certain that this will not happen. If nuclear protection were guaranteed by the United States and the Soviet Union jointly, some nations would be less likely to be, or at least to feel themselves, compromised. But in many cases joint guarantees will not be available and in other cases they may not sufficiently differ from the single protectorate. In the nineteenth century sucli a joint protectorate sometimes took the form of a dyarchy or condominium, yet the nations protected still felt themselves to occupy a somewhat invidious status. This is one of the nuajor reasons why we argue for the eventual necessity of regional military organizations which can guarantee a credible and reliable tit-for-tat retaliation and therefore eliminate the necessity for such hierarchical relationships.

\section{Limiting Proliferation to Multinational or International Organizations}

The objective of limiting proliferation is met reasonably satisfactorily if future proliferation is limited to regional or other international organizations. At the same time, one nuay hope to reduce the number of national nuclear powers. This was in fact the intent of the so-called European clause which the United States supported at the current Geneva negotiations. This original United States proposal for a multilateral force was plagued by many political and technical command and control problems. However, the distinctions made in this paper between a tactical doctrine of strictly proportionate tit-for-tat retaliatory responses and one of 
escalation, and between what we will call interior and exterior escalation, ${ }^{b}$ may alleviate many of the problems faced by the premature and imperfect United States proposal.

Limiting proliferation to regional military organizations is a reasonably satisfactory solution to the problem of providing nuclear protection without forcing any country into an unduly inferior position. Such organizations can guarantee a credible and reliable proportionate response to any nuclear aggression against any member of the regional pact or any nation covered by a multinational guarantee. The regional nuclear pact might even set up a multinational force, perhaps under United Nations control, whose purpose would be to provide for a non-national tit-for-tat retaliation.

II

\section{MINIMAL USE OF NUCLEAR WEAPONS}

Can the symbolic and political usefulness of nuclear weapons be reduced to the point where they would have a minimal effect on international affairs? This question may at first suggest a visionary goal, or an extreme standard by which to judge nuclear control policies. It raises the question of whether in the long run nuclear weapons can be defunctionalized in intense crises as well as during a détente, and rendered useless not only as militarily usable objects but even as symbols, bargaining counters, and threats. This may sound-and perhaps properly-like a criterion which could be net only through universal and complete disarmament. But the question we have in mind is not whether nuclear weapons can be eliminated in the pliysical sense, or even limited in number. Rather, we hope that raising this issue will focus attention on the actual and perceived usefulness of these weapons, especially on the prestige attached to their possession, and on their standing as legitimate instruments of national policy. In the absence of an effective world government, universal and complete physical disarmament does not appear feasible; nevertheless, other possibilities of relatively effective political and psychological "disarmament" measures should not be disregarded.

\section{A. Making Nuclear Weapons Seem Relatively Useless}

It should be clear that nuclear weapons today are considered to be useful in a variety of ways, not only as answers to immediate national security problems. To the nation possessing them they represent prestige, glamor, technological advancement, and a hedge against all kinds of undesirable events. Nuclear weapons inspire awe as well as terror, or rather awe mixed with terror. For these reasons we liave formulated our

${ }^{6}$ See discussion in section II B. infra. 
criterion to read "seem" relatively useless. We would hold out the hopelet us call it only a hope-that nuclear weapons can be "deglamorized" and that prestige may come to be attached to the nonpossession of nuclear weapons or to shared ownership through the medium of a multinational nuclear organization. We would also hope to cultivate in those countries that already possess nuclear weapons an attitude that their use-either politically or militarily-should be severely constrained. Those nations which already have nuclear weapons would then have to de-emphasize their value. The United States could no longer base its claim to leadership of the Western world on its possession of $90-95 \%$ of the world's nuclear striking power. It is exactly this kind of claim, explicitly equating political leadership with nuclear power, which is likely to make a nonproliferation system unattainable or unstable. Thus it is quite clear that this claim, implicitly or explicitly asserted by the United States, played an important if not central role in spurring the French to achieve nuclear status-a French program begun before de Gaulle. Regional or international nuclear organizations can be made legitimate means of preserving both nuclear security and independence, and even of gaining knowledge and experience about nuclear matters. Acceptance of this proposition would strengthen the attitude that, with the possible exception of the two super-powers, it is both unwise and immoral to have national nuclear weapons.

Part of what we have in mind is stimulation of a global anti-nuclear attitude comparable in some ways to the current attitudes of anti-colonialism and anti-racism. While there are many pro-colonial and perhaps even pro-racist arguments that may have some merit, at least in a sophisticated formulation, these are for the most part dismissed without a hearing in popular discussion and debate. The authors hesitate to support antiintellectual biases or to increase the partisan nature of current discussions, but we feel that if there must be bias and partisanship, an anti-nuclear policy should attempt to make these emotional attitudes less favorable to the dispersal and use of nuclear weapons. The analogy is worth consideration: Colonialism and racism today have almost none of the seeming utility and powerful prestige and authority they enjoyed two or three generations ago. They are "out," with the deviators feeling increasing pressure. We believe it not impossible that sometime in the next few decades the national possession of nuclear weapons, aside perhaps from possession by the United States, the Soviet Union, and China, might come to seem equally illegitimate. Of course anti-nuclear sentiment might then flourish-as it does sometimes today —in an irrational, indiscriminate, or partisan manner, so that any nation which "legitimately" had to rely on nuclear weapons for its self-defense might become a pariah. For this 
reason there are obvious disutilities in anti-nuclear passion. Nevertheless, it seems important to begin developing institutions or stable norms that could make global anti-nuclear sentiment sober and beneficial.

\section{B. Limiting Nuclear Weapons to Proportionate Retaliation}

One way to develop such an attitude might be to construct a world system in which the use of nuclear weapons is viewed as illegitimate except when limited to proportionate retaliation against nuclear attack. Each nuclear power would then liave a declared policy of not using nuclear weapons first, and of responding to a first attack only in corresponding degree and kind. If the nuclear threshold were broken, the preset policy would be (to put it in Biblical fashion) not only to take "an eye for an eye," but to take at most an eye for an eye. Between equals it would be considered legitimate to do this to the extent of exchanging a city for a city.

This may seem relatively stark, or perlıaps unrealistically intellectual, to those who regard the present world situation as both tolerable and durable. Certain auxiliary principles miglit lessen to some extent the stark simplicity of this nuclear lex talionis. The code of Hammurabi allowed for a fixed but proportionate escalation against "inferiors." The rule might also be modified to exempt "interior escalation"-in other words to provide that first or continued use of nuclear weapons against an opponent's forces operating in what is mutually recognized as one's own territory is not a legitimate occasion for the opponent's retaliation. But with these exceptions, there would be no deliberate escalation in this system. And even sucl seemingly reasonable exceptions as those discussed above may be undesirable if they tend to make the national possession of nuclear weapons seem desirable.

To prevent misinterpretation of an intended tit-for-tat response, sliglit underescalation might be advisable. Furthermore, within the limits of technical capabilities and political circumstances, it might be advisable to select on an ad loc basis a different kind of target in retaliation-say a naval flotilla or an isolated industrial center for a city-or indeed in certain special circumstances to use non-nuclear means to enforce the lesson that nuclear weapons are not to be used. In practice the lex talionis need not be absolutely inflexible in order to be effective; the doctrine of justifiable reprisal, often invoked in the nineteenth century, offers better analogies than does the literal practice of "eye for an eye" retaliation among some primitive peoples.

Perliaps some other idea could be found, less objectionable than the lex talionis, that could be adapted to twentieth century nuclear control problems. Operative ideas of world order and international affairs, low- 
ever, seem to be very rare. In recent generations there have been perhaps only two-the idea of collective security, which partly inspired the collective defense of the North Atlantic Alliance, and the idea of a balance of power, which partly inspired the public understanding of "containment." In recent years, however, the United States has been moving away from reliance on collective defense and containment, and has begun to implement ideas of limited war, arms stability, controlled response and proportionate retaliation. A "talionic" strategic doctrine, and arrangements to implement it, would actually be in line with much current Western and United States policy and with much emerging political-strategic thinking. ${ }^{6}$ A long-range nuclear control policy might thus be developed that extends, makes explicit, and institutionalizes the profound disposition toward proportionate response that is now widely held among American officials. This disposition also exists in other countries and might very well increase as more nations gain experience with nuclear arms. In short, a "new" idea for world order-nuclear lex talionis-may be emerging and an arrangement based on this idea could go a long way toward making national ownership of nuclear weapons seem unimportant if not undesirable.

Some might make the following criticism of our specific proposal of "tit-for-tat": If this should be adopted as a strategic doctrine, the idea behind it might radiate into all international dealings. To adopt the lex talionis as a norm of international justice is to take a backward step, to adopt a barbaric standard. International standards of justice should be attractive and uphifting, like those of the Charter of the United Nations, not forbidding and demeaning, like "an eye for an eye, and a tooth for a tooth."

In reply, we would point out that the lex talionis is not obviously barbaric, since it is much used today in nornal international interactions. As a primitive standard, it is inappropriate for use by the established courts in a civilized society. For this very reason, however, it might well be the appropriate standard of justice where there are no courts or poice, and almost none of the elements of law, inutual trust and "good faith" which characterize civilized society. It is easily compreliensible and does not require elaborate deliberation for its enforcement, as do the inore complex standards of distributive and corrective justice in such society. In many situations it is probably much more practicable than exclusive reliance on counterforce retaliation. Less barbaric than a standard which threatens total destruction of others and oneself, lex talionis could act as a check on excessive behavior springing from vengeance and other passions. It represents probably as ligh a standard of justice as nations

${ }^{6}$ See discussion in H. KaHN, ON Escatatton: Metaphors and Scenartos (1965), particularly the note on pages $185-86$. 
have ever yet achieved, or are ever likely to achieve consistently, given conditions of international anarchy. It compares favorably with recent attempts of several major nations to preserve or restore peace without trying to settle the underlying controversies.

There are those who believe that no concept of world order and ininternational justice is practical, and there are those who believe that justice under conditions of anarchy should produce the same benefits as justice under conditions of civility and fellow-citizenship. We disagree with both these opinions, and thus depart from some versions of both "realist" and "idealist" trends of thought. Instead, we argue that lex talionis could provide a general standard of conduct appropriate to anarcliy-at least among equals. It need not debase and might even elevate the normal level of international intercourse.

III

DETERRENCE AND DAMAGE-LIMITATION

\section{A. Deterrence}

No scheme can completely assuage the multifarious fears that arise as a consequence of the very existence of nuclear weapons; for even in the case of total disarmament, fears will remain that the weapons might again come into existence or that disarmament was not complete. Nor will any scheme completely eliminate nuclear weapons from the calculations of statesmen and, in fact, it might be undesirable to try to go that far. The major, perhaps sole, legitimate function of nuclear weapons should be to deter-to answer the threat or use of nuclear weapons. Aside from this the world should psychologically be relatively close to a situation in which nuclear weapons did not exist.

The reason for the emphasis on the word "relatively" may need clarification. A widespread belief that the world was completely non-nuclear would clearly result in some undesirable effects. For example, nations today are very careful in non-nuclear confrontations simply because they fear escalation to nuclear weapons (or the procuring of nuclear weapon systems by their opponents). These inhibiting fears have some desirable consequences. But we may be able to eat our cake and have it too. Such fears of nuclear escalation or production will still exist despite measures that successfully himit proliferation and reduce the likelihood of the use of nuclear weapons. Therefore some of the deterrent aspects of such potential escalation would not be eliminated. Moreover, excessive fears may be too inhibiting and therefore dangerous. Many have argued that the present excessive fear of nuclear weapons has often weakened the will and resolve of the western powers in various crises. 
Ideally, the fear of deterrence should be limited by the effective elimination of particularly stark threats, or even any threat of first use of nuclear weapons for nuclear intimidation or blackmail. Althougli the current atmosphere of détente and nuclear incredulity seems to reduce the likelihood of intimidating threats and attacks, recent Chinese tests have indicated that nuclear intimidation remains a serious problem.

Provisions for a credible talionic response with the remote possibility for escalation would meet almost all legitimate and necessary requirements of deterrence. Of course, even the most credible threat of tit-for-tat retaliation might not work on a "Hitler." Some future leader miglit be willing to accept tit-for-tat retaliation-in part to be able more credibly to threaten further attack or at least to demonstrate that he is willing to pay sucli a price. Under these circumstances there are only a few practicable possibilities: (1) large-scale escalation to the point where the retahation would cause major damage; (2) some kind of preventive war whicl might include large elements of mutual destruction; (3) appeasement by yielding to some of the demands of the nuclear "Hitler"; or (4) some combination of all three of the above tactics or threats.

Fortunately, sucl extreme beliavior is unlikely, and even a "Hitler" miglit not be able to survive with unimpaired power and authority if faced with tit-for-tat retaliation. In the world as it is likely to develop, such behavior seems somewhat more probable on the part of a smaller or less developed country with a much smaller nuclear capability. In such a case the larger nations or organizations would probably prefer to disarm that country forcibly-risking or accepting nuclear retaliation-rather than to live with an ever-present threat of reciprocal proportionate attacks. This is why we suggested as a model the undemocratic code of Hammurabi rather than the simpler and more equitable "eye for an eye" Biblical principle. Except for the possibility of a new "Hitler," some form of lex talionis, if it could be made reliable, would adequately deal with the plausible problems of nuclear intimidation.

\section{B. Damage-Limitation}

All agree that it is important to prevent war. But almost everyone recognizes that weapons exist and war can still occur; it is therefore important that if it occurs, it slould not be catastrophic. There may, of course, be a reciprocal relation between the hikelihood of war occurring and the probable extent of danage the war would cause. It is often argued that the greater the potential catastrophe, the less likely the war. While this may be true for certain issues and certain kinds of war, there are in fact important factors tending the other way. Moreover, one 
should be willing to trade a small increase in the likelihood of war for an enormous decrease in the degree of catastrophe if war occurs. ${ }^{\text {? }}$

One of the prominent damage-limiting features under discussion is limiting retaliation to only "an eye for an eye, a tooth for a tooth." If this were the declared and operational strategy, the incentive to limit damage would be sustained on both sides before, during, and after a particular attack. The side planning to attack would be induced to visualize concretely the likely retaliatory damage to itself; it must calculate that it miglit be re-attacked in corresponding degree and kind even if it were not absolutely certain of the exact form such a response would take. Moreover, the prospective viction of the initial attack would have been prepared and, hopefully, committed to respond proportionately even before the attack occurred. If committed to react according to the nuclear lex talionis the attacked state would be unlikely either to capitulate or to insist on enormous bonus damage. Therefore, during, and immediately after the initial attack the aggressor would have a futher incentive not to launch a massive attack since the one attacked has credible alternatives other than surrender or spasm reply with consequent suicide because of the subsequent spasin retaliation. If attack and proportionate re-attack occur, the incentive to limit further dainage should still persist. And, while the deterrent value of a possible spasm or other disproportionate response is greatly reduced under these conditions, it is not completely lost. The other side cannot be certain that its opponent will not change its policy and resort to a major nuclear escalation-despite all its proposed prewar plans and theories. Thus assuming for the moment what is surely reasonable for most countries under most conditions-that the credibility of an explicitly threatened "all-out" unrestrained response is low-then its replacement by a smaller but more credible threat may not represent any decrease in deterrence. There may even be a gain in deterrence, since the possibility of a spasm response still looms in the background.

Damage-limiting in the ordinary sense is only one potential benefit of the proportionate response; the other is the increase of the deterrent value of a given amount of violence. Automatic response, being "locked in" to a specified course of action, is more dissuasive than flexibility combined with a reputation for caution. It may also be much more dissuasive than flexibility or suppleness combined with threats "to tear an arm off" and accept annihilation in response. Under the envisaged conditions, then, it is quite possible that damage-limiting and deterrence will be surprisingly convergent rather than contradictory, and the issue of trading off one against the other would become much less agonizing

\footnotetext{
7 By "war" here we mean any use of nuclear weapons.
} 
than it is ordinarily thought to be. Further, it should be reasonably clear that in most cases a failure of deterrence which resulted in a tit-for-tat or similar reciprocal exchange and then a subsequent de-escalation is likely to result in a strengthening rather than a weakening of the basic system.

\section{IV}

\section{Flexibitity and Permanence \\ A. Ability to Withstand Crises}

A long-term policy that attempts to limit the proliferation and functions of nuclear weapons should be resilient. That is, it should be able to withstand crises, war, breaches and a local or even global end of the détente. To stake everything on the effective workings of deterrence or on limiting proliferation to five or any set number of countries, or to inflict a burden on the anti-nuclear "good citizens" while tempting and rewarding the "delinquents" would tend in the direction of fragility, not resiliency. An acceptable long-tern program must allow for failure of deterrence, abstentions, and even partial failures of the system without permitting the total structure to collapse.

Under the suggested system one could have all kinds of local failureseven a total one in a given region-without requiring other regions either to intervene in the first region or to suffer some loss themselves. Furthermore, no matter low extensive the regional proliferation or prolonged and violent the war, a world-wide system composed of interacting but basically independent local systems slould be able to continue operating. Indeed, if a war ended with a more or less equal level of destruction resulting from tit-for-tat tactics and there was a final de-escalation without much positive net gain by one side or the other, the system would probably be strengthened rather than weakened. Similarly, if in a conventional war a desperate nation used nuclear weapons to prevent a disastrous defeat and then de-escalated after the tit-for-tat retaliation, its use of nuclear weapons might in fact be successful in that it fulfilled its immediate tactical objectives; yet at the same time the system would once more as bikely be strengthened as weakened. This would not, of course, be true if the initiator of the use of nuclear weapons actually achieved major positive gains rather than averted a very disastrous defeat.

\section{B. Negotiability}

A nuclear control policy should be treated as no different in kind from any other national policy; it should be regarded in all cases as a legitimate subject of international negotiation. This criterion clearly cannot be niet at the present time. It is unlikely that any European nation would be 
willing today to see the West Germans participate in any kind of a multinational nuclear force. Similarly, most people would consider it futile to raise the issue of Japanese participation now. The current situation, however, will probably not last longer than another decade. Consideration of the issues of nuclear control today may provide concepts acceptable as guides for those countries which will enter the field of nuclear negotiation in the near future. While the specific concepts put forth by the authors may not prove acceptable, we suspect that in a modified form they will be as acceptable as any other proposals that meet the criteria in this paper.

A very limited strategic defense community might be negotiable, while a full defense would not be, because the hmited community would permit its members to deal with some relatively remote contingencies without requiring intimate and systematic political and economic cooperation. Particularly if the nuclear force were based upon Polaris-type submarines or ships, it could be relatively small; it would not involve the number of agonizing or difficult specific political and administrative decisions required in a full defense community. The himited strategic defense community clearly raises more issues than most current inultinational organizations, but it probably raises fewer than did either the European Coal and Steel or Common Market communities. If the defense commmunity succeeded in fulfilling its objectives, it would not lead to many other political consequences. Therefore one could hope to reach agreement on it $i$ i a relatively apolitical way. In connection with an Asian defense community, for exaniple, a plausible argument can be made that the Asian powers, without reaching basic agreement on most political issues, can all agree that they do not wish nuclear weapons to have a role in the political dialogue. Therefore, the Asians might all agree on a special kind of strategic treaty defense community which, if successful, might considerably aid the effective removal of nuclear weapons from the dialogue and yet require no other major political changes.

\section{Freedom from Prior Commitments}

A nuclear control policy should not have been foreclosed or embarrassed by prior commitments or alignments. This is a current issue today because the attenipts to strengthen the current nonproliferation treaty now being negotiated in Geneva miglit not meet the criteria of this paper. Even if the treaty makes some provision for nuclear sharing in Europe, it would not authorize a multinational Asian or other regional force. This is not a crucial point since parties desiring to form such forces could take advantage of the treaty's liberal provisions for withdrawal. However, it 
is a major purpose of this article to interest statesmen in conducting foreign policy so that it will not hamper the evolution of a more satisfactory long-run nuclear pohicy. Even if freezing the current status quo were accepted as the best policy, an unsuccessful attempt to achieve this end could destroy the relatively stable situation which exists at present. After the negotiation process had resulted in the destruction of other less desirable but still satisfactory options for nuclear policies, perpetuation of the current distribution of nuclear power might turn out to be impossible. Choosing between a policy whicl is feasible but only adequate and one whicl is problematical but highly desirable is always difficult. We have not examined all aspects of this particular choice in this article, but hopefully we have focused attention on the necessity for care in choosing current policies so that desirable future programs are not unnecessarily foreclosed.

It is particularly inportant to note that the proposed multinational force-truly independent of any superpower sponsor and substantially committed to tahonic responses for its tactics-is quite different from the multilateral force previously suggested by the United States. These differences miglit well be emphasized since the old multilateral force proposals have gained a rather bad reputation. Because of the controversial history of the idea of a multilateral force the United States should not play an active role in pursuing most of the concepts advanced in this paper. Although the issues should be raised and considered by the United States and others, discussion inaugurated by private persons is preferable to overt and vigorous official American sponsorship.

\section{Freedom from "Politics"}

The "political" phenomena to be avoided include the following: seeking maximum power and prestige in the short run rather than optimum power and prestige in the long run; indulging in unnecessary cant; disregarding technical, political or other facts which do not serve one's purposes or which require some effort to understand; preferring tactics over strategy; and tending to "normalize" or "routinize" everything, to see everything from the standpoint of prevailing administrative or political habits.

The appearance of "political" phenomena is most probable if a proposal contains some particularly objectionable points on which doubt and opposition can concentrate. If one can design a proposal with few essential features there is much more room for bargaining and compromise. Therefore to design and institute a long-term arrangennent for the control of nuclear weapons may require a sort of artistry in relating basic principle 
to programmatic or administrative details. The criteria of this paper allow sufficient freedom to do this, while providing enough constraints to focus discussion.

Nevertheless, a desirable policy for long-term control of nuclear weapons would at least initially require an unusual degree of cooperation even if it did not require a basic re-shaping of the international order. For instance, the proposal advanced might require conduct concerning nuclear control issues to be above the normal level of allied relations during the last ten years and to approach the higher level (as it seems now) of the 1940's and early 1950's.

\section{E. Appropriateness as an Object of "Sudden Diplomacy"}

Many analysts argue that a crisis may eventually occur which will unsettle familiar policies in suclı a way as to allow or impel new initiatives-even relatively extreme ones. They urge the United States and its allies to be prepared to exploit sucl crises with a view to achieving desirable changes in the international order. In any case the North Atlantic Alliance may soon reach a point where the United States has to produce or invite a flexible set of suggestions for either greater European independence in nuclear matters or a more credible guarantee. Domestic opinion or a foreigu crisis may pusl the Umited States itself into saying that it cannot indefinitely continue to risk 100 million or so American lives for the sake of Europeans, and that the continuation of an American guarantee for the next several years depends on the Europeans' eventually taking some initiative in securing their own nuclear defense. It is still nore likely that other European countries will follow the Gaullist lead and adopt assertive or independent policies. In any case, the United States should now be thinking about the consequences of these developments and the acceptable and unacceptable features of various actions the Europeans might propose. At the minimum it seems reasonable to foresee an insistent denand from some of the current non-nuclear nations to obtain nuclear weapons. It also seems likely that it will not be sufficient to urge selfcontrol or unilateral restraint.

\section{F. Permanence with Provision for Future Developments}

A nuclear policy should be potentially permanent and yet sufficiently flexible to hedge against events and exploit opportunities in both negotiation and operation. Tlis is an important standard by which to judge policy proposals, but while in many cases its implications are plain, both injunctions are often ignored. Even if a proposal contains attractive ideas or principles whicls respond to real needs and seem generally sensible, it may be reasonable to reject it if current needs are not excessively pressing 
and the proposal forecloses preferable future possibilities. Therefore a valid judgment of any proposal requires weighing its immediate desirability against its eventual compatibility with needs and pressures whicl are likely to develop.

A policy to deal with the long-term problem of nuclear weapons should be able to survive and even grow in crises and misfortunes. However, the sense of steadiness and continuity should not foreclose the possibility of major innovations, as well as stable development, resulting from increased experience and confidence or new conditions and attitudes. Most important, a policy should not attempt to "make history by design" in a way that presupposes detailed and skillful human control of the futureparticularly if it is bucking powerful human impulses. It should attempt only to establish viable institutions and customs which can also encourage-by example, elaboration, development, or absorption-much more comprehensive, just and reliable arrangements.

\section{CONCLUSION}

Let us summarize this paper by suggesting that the current, probably temporary, but otherwise nearly satisfactory nuclear stability is due mainly to the lack of immediate and effective national pressures for proliferation. The four current major candidates for nuclear status, Germany, Israel, India, and Japan, appear unlikely to act in the foreseeable future. Germany cannot act for political reasons; both its allies and its enemies would not tolerate independent German action. Israel cannot act because the United States has made clear that it would leave Israel to face the Arab countries and their Soviet allies itself if Israel acquired nuclear weapons. Partly for similar reasons, India will probably not act; it desires both United States and Soviet support. In addition, many Indians seem more afraid of Indian than of Chinese nuclear weapons, and, most important, Indian has long had a non-nuclear position. Japan has not begun a program, mainly because of internal political pressures, but it can be argued that these will change in five to ten years. ${ }^{8}$ There is no other country that currently exhibits serious interest in obtaining nuclear status. But, looking ahead ten to fifteen years, one can list almost twenty countries likely to be interested. If one looks ahead twenty to thirty years, the number is roughly half the countries of the world (fifty or so).

Although peculiar and temporary circumstances keep the problem of probiferation in abeyance today, there is little reason to think that it has been solved or that treating it on an ad hoc basis will result in preserving

8 See discussion of nuclear proliferation in H. Kahn, Uncertain Road to the 21st Century, Trenss, Jan.-Feb. 1967, at 2, 10. 
the current situation for ten to twenty years. And we should not deceive ourselves by focusing on measures that work well, if at all, only because inevitable counterpressures have not yet intensified. We must debate this subject, think about it, discuss it, accumulate ideas, and create an intellectual framework which will allow various countries to satisfy their various ambitions without jeopardizing world stability. The proposed nuclear nonproliferation treaty does not fulfill these criteria. Without arguing that it should not be sigued, one can conclude that it is not satisfactory as a long-range nuclear control policy. 